\title{
T Cell Large Granular Lymphocyte Leukaemia with Cutaneous Infiltration
}

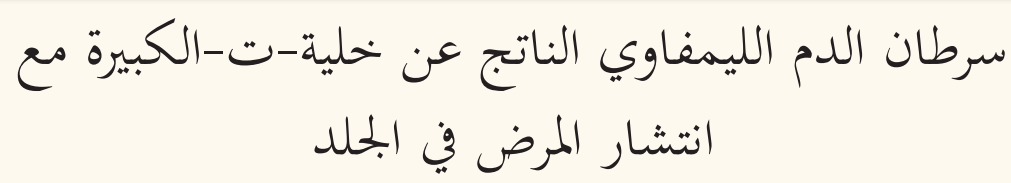

Sir,

A 63-year-old woman was referred to the Department of Dermatology of the Complejo Hospitalario de Granada, Granada, Spain, in 2016 with painful erythematous desquamative nodules and papules of three weeks' duration. She had a history of stage I infiltrating ductal carcinoma of the breast, unilinear myelodysplastic syndrome with granulocytic involvement, chronic neutropaenia and a diagnosis of $\mathrm{T}$ cell (cluster of differentiation $[\mathrm{CD}] \mathrm{8}^{+}$) large granular lymphocyte (LGL) leukaemia. Upon examination, the papules were distributed mainly on the forehead and right upper and lower limbs [Figures $1 \mathrm{~A}-\mathrm{C}$ ]. Some of the lesions were fluctuating and suppurative, while the others were of a solid consistency. The examination also revealed oral aphthae which were causing dysphagia [Figure 1D]. At referral, the patient was receiving treatment with $50 \mathrm{mg}$ of low-dose cyclosporine on alternate days and $300 \mu \mathrm{g}$ of granulocyte-colony stimulating factor per week, to which a partial response was noted.

Given the suspicion of leukaemia cutis, a biopsy of the lesions was taken. The findings were compatible with a diagnosis of folliculitis, with polymerase chain reaction and direct immunofluorescence tests negative for Mycobacterium tuberculosis and immunoglobulin (Ig) G, IgA, IgM and complement 3 deposits, respectively. Consequently, treatment with $500 \mathrm{mg}$ of cloxacillin every six hours and $15 \mathrm{mg}$ of prednisone per day was initiated; however, there was no evidence of clinical improvement. Successive biopsies indicated systemic vasculitis caused by granulomatosis with polyangiitis. Eventually, nine months after the onset of the symptoms, a final biopsy revealed that the papules represented the cutaneous infiltration of LGL leukaemia [Figure 2], associated with secondary interstitial granulomatous dermatitis. At the time of writing, the patient was being treated with combined cyclophosphamide, vincristine, doxorubicin and prednisone (CHOP) therapy which resulted in the resolution of her cutaneous symptoms [Figure 3]. There was no evidence on computed tomography of any systemic progression to other organs.

LGL leukaemia is a low-grade lymphoproliferative disorder characterised by monoclonal expansion in the peripheral blood and bone marrow with either an activated cytotoxic T lymphocyte (i.e. CD8 or CD57+ cells) or, less frequently, a natural killer (CD3, CD8- or CD56 ${ }^{+}$cells) phenotype. ${ }^{1}$ Generally, LGLs represent $10-15 \%$ of circulating mononuclear cells and are identified morphologically by their large size and rounded or dentate nuclei and abundant cytoplasm with azurophilic granules. ${ }^{2}$ Clonality has been confirmed by $\mathrm{T}$ cell receptor gene
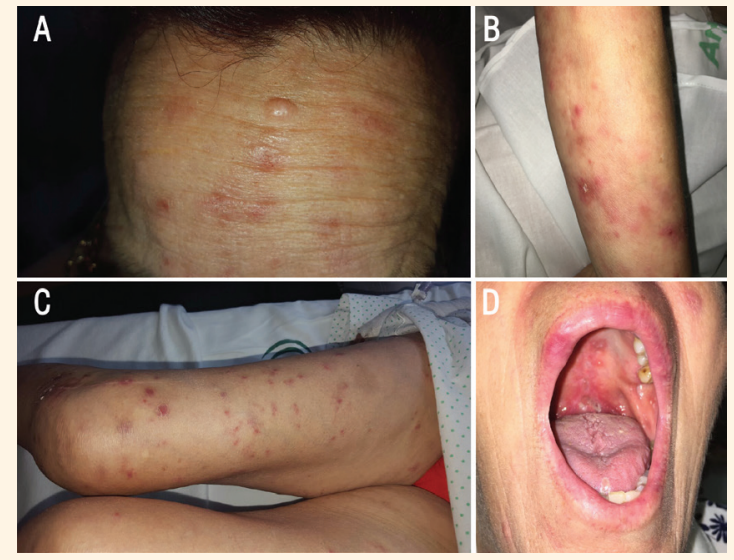

Figure 1: Photographs of infiltrated papules and patches on the (A) forehead and right (B) upper and (C) lower limbs of a 63-year-old woman with large granular lymphocyte leukaemia. The clinical examination also revealed (D) major aphthae in the oral cavity.

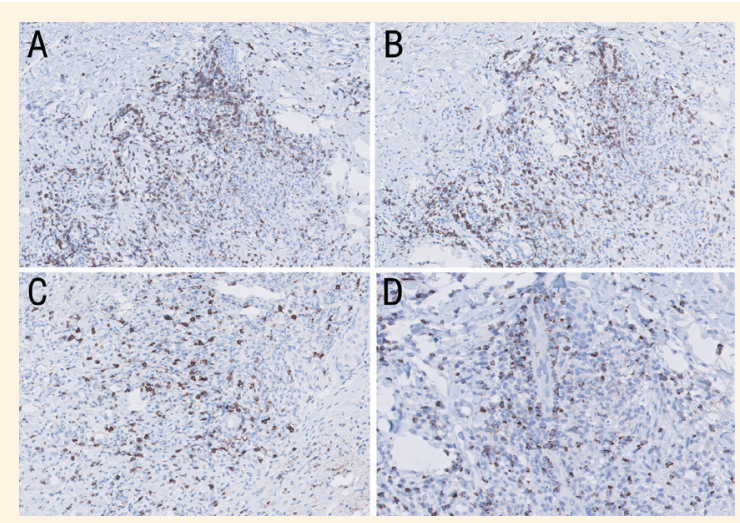

Figure 2: Immunohistochemistry panel at x20 magnification showing positive (A) cluster of differentiation (CD)2, (B) CD8, (C) CD57 and (D) T cell intracytoplasmic antigen 1 stains. 


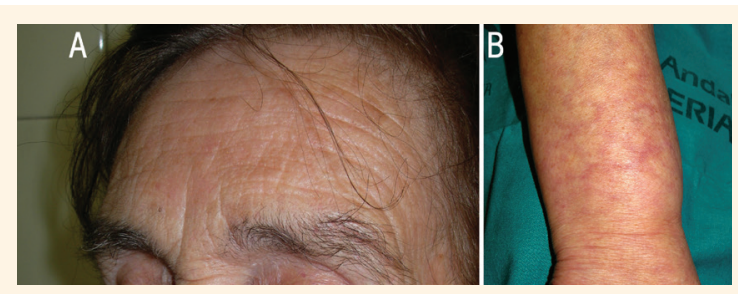

Figure 3: Photographs of the (A) forehead and (B) upper right limb of a 63-year-old woman showing the resolution of large granular lymphocyte leukaemia-infiltrated papules and patches following chemotherapy treatment.

rearrangement testing. ${ }^{3}$ Frequently, LGL leukaemia is related to autoimmune diseases such as Felty's syndrome and has a chronic and indolent course, with a mean survival of 10 years. ${ }^{4,5}$ Occasionally, the behaviour of this form of leukaemia can be more aggressive, especially in cases with a natural killer phenotype. ${ }^{2}$

Approximately one-third of patients with LGL leukaemia are clinically asymptomatic, with neutropaenia observed in up to $85 \%$ of cases. ${ }^{3}$ The disease is sometimes associated with arthritis, cytopaenia and splenomegaly, but only exceptionally with lymphadenopathy. ${ }^{4}$ Cutaneous infiltration is rare and usually manifests as papules, nodules or, even less frequently, leg ulcers. ${ }^{4,6}$ Other reports have described LGL leukaemia patients presenting with generalised erythema and pruritus, petechiae and disseminated granuloma annulare. ${ }^{6-8}$ The indolent course of the disease usually permits a 'wait and see' approach, although indications for treatment include recurrent infections, anaemia, symptomatic splenomegaly or severe B symptoms. ${ }^{5}$ Immunosuppressants are the first line of treatment, such as methotrexate, cyclosporine, or cyclophosphamide; these monotherapies are effective in almost 50\% of patients by correcting cytopaenia without eradicating the leukaemia cells. ${ }^{9}$ However, for those with refractory or highly aggressive forms of the disease, $\mathrm{CHOP}$ therapy or a similar chemotherapy regimen is recommended. Trials with purine analogues, alemtuzumab, bortezomib, splenectomies or allogeneic bone marrow transplants have resulted in variable outcomes. ${ }^{1,9}$

\section{"Ricardo Ruiz-Villaverde, ${ }^{1}$ Ahinoa Bueno-Rodriguez, ${ }^{1}$ Paula Aguayo-Carreras, ${ }^{1}$ Daniel Sánchez-Cano, ${ }^{2}$ Norberto Ortego-Centeno ${ }^{3}$ \\ ${ }^{1}$ Department of Dermatology, Complejo Hospitalario de Granada, Granada, Spain; ${ }^{2}$ Department of Internal Medicine, Hospital Comarcal Santa Ana de Motril, Motril, Spain; ${ }^{3}$ Systemic Autoimmune Diseases Unit, Hospital Universitario San Cecilio, Granada, Spain \\ *Corresponding Author's e-mail: ismenios@hotmail.com}

\section{References}

1. Lamy T, Loughran TP Jr. How I treat LGL leukemia. Blood 2011; 117:2764-74. doi: 10.1182/blood-2010-07-296962.

2. Lois Iglesias A, Sifuentes Giraldo WA, Bachiller Corral J, Saiz González A, Brito Brito E, Zea Mendoza A. Large granular lymphocyte leukemia as a complication of rheumatoid arthritis. Reumatol Clin 2012; 8:365-7. doi: 10.1016/j.reuma.2011.12.014.

3. Mohan SR, Maciejewski JP. Diagnosis and therapy of neutropenia in large granular lymphocyte leukemia. Curr Opin Hematol 2009; 16:27-34. doi: 10.1097/MOH.0b013e32831c8407.

4. Duarte AF, Nogueira A, Mota A, Baudrier T, Canelhas A, Cancela J, et al. Leg ulcer and thigh telangiectasia associated with natural killer cell CD56(-) large granular lymphocyte leukemia in a patient with pseudo-Felty syndrome. J Am Acad Dermatol 2010; 62:496-501. doi: 10.1016/j.jaad.2009.03.001.

5. Liu X, Loughran TP Jr. The spectrum of large granular lymphocyte leukemia and Felty's syndrome. Curr Opin Hematol 2011; 18:254-9. doi: 10.1097/MOH.0b013e32834760fb.

6. Sia PI, Figueira E, Kuss B, Craig J, Selva D. T-cell large granular lymphocyte leukemia in the lower eyelid. Ophthal Plast Reconstr Surg 2016; 32:e126-8. doi: 10.1097/IOP.0000000000000297.

7. Granjo E, Lima M, Correia T, Lisboa C, Magalhães C, Cunha N, et al. Cd8(+)/V beta 5.1(+) large granular lymphocyte leukemia associated with autoimmune cytopenias, rheumatoid arthritis and vascular mammary skin lesions: Successful response to 2-deoxycoformycin. Hematol Oncol 2002; 20:87-93. doi: 10.1002/hon.695.

8. Granjo E, Lima M, Lopes JM, Fernandes JC, Antunes I, Candeias J, et al. Response to cyclosporine in a patient with disseminated granuloma annulare associated with CD4+/CD8+(dim)/CD56+ large granular lymphocytic leukemia. Arch Dermatol 2002; 138: 274-6. doi: 10.1001/archderm.138.2.266.

9. Lazaro E, Caubet O, Menard F, Pellegrin JL, Viallard JF. [Large granular lymphocyte leukemia]. Presse Med 2007; 36:1694-700. doi: 10.1016/j.lpm.2007.06.002. 